\title{
EFFECT OF NATURAL VENTILATION AND WIND DIRECTION ON THE THERMAL PERFORMANCE OF A BUILDING CEILING
}

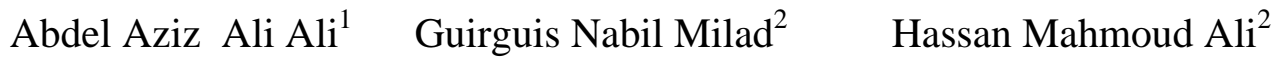 \\ ${ }^{1}$ Shoubra Faculty of Engineering, Banha University, Egypt \\ ${ }^{2}$ housing \& Building Research Center, Cairo, Egypt
}

\begin{abstract}
Natural ventilation is rapidly becoming a significant part in the design strategy of buildings in situations where electricity is scare or non-existent and saving energy becomes highly important. The aim of present work is to reduce the ceiling temperature by natural ventilation through different opening locations (one window in the front façade and the other window in the rear wall) with sill height ratio of $0.27,0.36,0.45,0.54$, and 0.63 . Wind tunnel and smoke tunnels were used to investigate the effect of opening locations on the temperature and heat transfer coefficient of a ceiling of a naturallyventilated room. Here, the ANSYS CFD software was used to determine the flow characteristics in the ventilated room with different opening locations and wind direction. Better flow pattern and heat transfer from the heated ceiling are observed when the front and rear openings are located nearest to the ceiling and center, respectively. An experimental correlation was obtained to predict the influence of sill opening height ratio of front and rear walls on the average heat transfer coefficient ratio of ceiling $\left(h_{a v} / h_{O}\right)$ where $\left(h_{o}\right)$ is the heat transfer coefficient in case of no wind.
\end{abstract}

\section{KEYWORDS}

Energy saving, Heating ceiling panel, CFD, window location, Natural ventilation, Heat transfer.

\section{INTRODUCTION}

In previous years, natural ventilation has gained momentum as a suitable passive design strategy for buildings. Design guidance for buildings has been published by BRE [1], CIBSE [2], and BRESCU [3]. Many research works have been done in the field of thermal comfort by natural ventilation in buildings such as Vincent et al. [4] studied the effect of central courtyard on the natural ventilation in refurbished historic buildings, using wind tunnel modeling and computational fluid dynamic. Potangarana [6] developed a design tool based on the boundary layer wind tunnel testing and computational fluids dynamic studies. Results suggested that, although natural ventilation has traditionally been used for low rise buildings. Hassan M. A. et al. [9] studied experimentally and numerically the combined effects of the air flow (speed and direction) and window size on thermal comfort in buildings. Tine S. L., et al [11] studied single sided natural ventilation using a full-scale wind tunnel. The effect of wind velocity, direction and temperature difference on the air flow through the openings was discussed. Fernando M. and Jorge G., [13] estimated the natural ventilation flow rates through buildings.

In the present study an experimental and computational investigation were carried out to study the flow characteristics and thermal behavior of air in a ventilated room model with different opening locations.

\section{EXPERIMENTAL AND CFD WORK}

An experimental measurements and numerical computations (using ANSYS 2001) were conducted to evaluate the air flow characteristics inside a building model with different opening locations using a wind tunnel test facility which was designed, built and tested at the Housing \& and Building National Research Center by Guirguis et al. [15]. Various scaled-up test models with different opening locations were subjected to wind tunnel tests to study the ventilation characteristics inside buildings. The test models (Fig. (1)) were in the form of rectangular blocks of dimension $0.22 \times 0.22$ $\mathrm{x} 0.235 \mathrm{~m}$ and were fabricated from a plastic sheet of $0.003 \mathrm{~m}$ thickness (Plexiglas). The front and rear opposite walls have rectangular openings $(0.16 \mathrm{~m} \mathrm{x}$ $0.02 \mathrm{~m}$ ) with different locations. The window sill height ratios of the front $\left(\mathrm{y}_{\text {front }} / \mathrm{H}\right)$ and rear $\left(\mathrm{y}_{\mathrm{r}} / \mathrm{H}\right)$ measured from floor was varied as $0.27,0.36,0.45$, 0.54 , and 0.63 where $\mathrm{H}$ is the ceiling height. In the experiments, the ceiling was held at a constant heat flux $\left(410 \mathrm{~W} / \mathrm{m}^{2}\right)$. The ceiling of the model was provided with a heating plate. Twenty five thermocouples were used to measure the local ceiling temperature as shown in Fig.(1). Two thermocouples were used to measure the entering air temperature as well as inside the test model. The opening locations can be used to control the inside air temperature. This mechanism of ventilation depends on the outdoor conditions (dry temperature, humidity, and velocity). 


\section{COMPUTATIONAL WORK}

The nature of the air flow inside buildings is very complex, especially in the downstream region directly behind windows. The air distribution through a ventilated space can be computed from the CFD ANSYS program. The present results of air distribution are shown in the form of velocity vectors and contours. The CFD numerical results provide more comprehensive data than could be gathered in the experimental work.

\section{$\underline{\text { RESULTS AND DISCUSION }}$}

\section{EXPERIMENTAL RESULTS}

Cross ventilation of some spaces is usually needed to allow natural ventilation to take place at night time with the intention of removing heat gains accumulating through ceiling and exposed walls during day time. Inlet and outlet openings allow air to flow past the ceiling surface to set up a suitable convective circulation. Figures (4) and (5) show the effect of the front and rear opening locations on the normalized average ceiling temperature and heat transfer coefficient, respectively. The average ceiling temperature $\left(T_{a v}\right)$ was normalized with the indoor air temperature $\left(T_{a}\right)$ in the form of $\left(T_{a v}-T_{a}\right) / T_{a}$ and the average heat transfer coefficient $\left(h_{a v}\right)$ is normalized by the value of the average heat transfer coefficient $\left(h_{o}\right)$ evaluated for the model with heated ceiling and all openings are closed (No-wind). Ventilation from inlet opening $\left(\mathrm{y}_{\text {front }} / \mathrm{H}=0.63\right)$ to outlet opening $\left(\mathrm{y}_{\text {rear }} / \mathrm{H}=0.45\right)$ appears to reduce ceiling temperature to a minimum normalized value of 0.22 and raises the heat transfer coefficient of the ceiling to normalized value of about 9.4. This would increase air circulation and hence improve cooling effect. The ceiling appears to be cooled better when the inlet opening is located nearer to the ceiling $\left(\mathrm{y}_{\text {front }} / \mathrm{H}=0.63\right)$ while the outlet is almost in the middle of the rear wall $\left(\mathrm{y}_{\text {rear }} / \mathrm{H}=0.45\right)$. This would force air to follow an effective path between inlet and outlet. It may be observed that the ventilation with case $\left(\mathrm{y}_{\text {front }} / \mathrm{H}=0.63\right.$ and $\mathrm{y}_{\text {rear }} / \mathrm{H}=0.45$ ) is to achieve a higher air change rate past the ceiling than with case $\left(\mathrm{y}_{\text {front }} / \mathrm{H}=0.63\right.$ and $\mathrm{y}_{\text {rear }} / \mathrm{H}=0.63$ ) of cross ventilation. As the front opening shifts to floor $\left(y_{\text {front }} / H \leq 0.45\right)$, no effective change occurs in the $\left(h_{a v} / h_{o}\right)$ values when the rear opening height ratios are maintained at $0.63,0.54$, and 0.36. On the other hand, when the front opening locations move to the ceiling, a more significant increasing of $\left(h_{a v} / h_{o}\right)$ is observed from (3.1 - 4.1), (3.0 - 4.2), (4.6 - 5.4), and (6.9 -
9.5), when the rear opening ratios are maintained at $0.54,0.63,0.36,0.27$, and 0.45 , respectively. Figures (6) and (7) show the effect of wind direction on the normalized average ceiling temperature and normalized heat transfer coefficient, respectively for opening inlet locations $\left(\mathrm{y}_{\text {front }} / \mathrm{H}=0.63\right)$ and $\left(\mathrm{y}_{\text {rear }} / \mathrm{H}=0.45\right)$. The average heat transfer coefficient was normalized by the average heat transfer coefficient at angle of attack $90^{\circ}$ $\left(h_{90^{\circ}}\right)$. It is noticed that the normalized average heat transfer coefficient decreases rapidly from wind direction zero degree (normal to building facade) to $15^{\circ}$. As wind direction increases from $15^{\circ}$ to $75^{\circ}$ no significant variation in $\left(h_{a v} / h_{90^{\circ}}\right)$ is observed. It can be seen that, the normalized heat transfer coefficient at zero direction is greatest while for a direction of $90^{\circ}$ is lowest.

The experimental correlation of the average heat transfer coefficient ratio $\left(h_{a v} / h_{o}\right)$ is developed in terms of sill opening height ratios of the front and the rear in the following form:

$$
\left(\frac{h_{a v}}{h_{o}}\right)=a \cdot\left(\frac{y_{\text {front }}}{H}\right)^{b} \cdot\left(\frac{y_{\text {rear }}}{H}\right)^{c}
$$

The constant coefficients a, b, and c are a $=3.41$, b $=0.196$, and $c=-0.685$ with a maximum relative error of $10 \%$.

\section{COMPUTATIONAL RESULTS}

The effect of opening locations on the air movement (velocity distributions) in 3-D geometrically similar ventilated rooms is illustrated in Figure (3). The sill opening height has the values of $0.63,0.54,0.45,0.36$, and 0.27 of the wall height. The air was supplied from a rectangular front opening $\left(160 \times 20 \mathrm{~mm}^{2}\right)$ at sill height ratios of 0.27 , $0.36,0.45,0.54$, and 0.63 using a in groups $1,2,3$, 4 , and 5, respectively. The effect of opening locations on the air flow pattern is clearly predominant. With front opening sill height at 0.63 (group 5), the jet with a maximum velocity attaches to the ceiling by the effect of flow circulation when the rear opening location maintained at 0.45 and better ventilation is occurred specially at upper region of the model. As a result the air movement adjacent to the ceiling is improved and hence this situation allows a good amount of air to remove the heat convected from the ceiling to the inside air that was rejected through the rear opening. When front opening moves toward floor, the rear opening acting on the cool air jet and causes the jet to deflect downwards into the occupied zone where the ventilation inside the model at upper region of the model is attenuated and a wake region 
formation is appeared. Two wake regions are formed at upper and lower zones inside the model when the two openings are located at the center of the front wall.

\section{CONCLUSIONS}

From large amount of data colleted of temperature, velocity, and smoke flow pattern, present results can be summarized as follows:

1- The present numerical results give qualitatively a good discussion of the experimental results of heat transfer.

2- $\quad$ The highest air velocities were occurred close to the ceiling at yfront $/ \mathrm{H}=0.63$ and yrear $/ \mathrm{H}$ $=0.45$ (F5R3) and the highest value of $\left(h_{a v} / h_{o}\right)$ is found.

3- $\quad$ Average temperature of ceiling decreases as the front sill opening height ratio (yfront/H) increases.

4- When the front opening move toward the ceiling, a more significant increasing of $\left(h_{a v} / h_{o}\right)$ is observed from (3.1 - 4.1), (3.0 - 4.2), (4.6 - 5.4), and (6.9 - 9.5), with rear sill height opening ratios are maintained at $0.54,0.63,0.36$, 0.27 , and 0.45 , respectively.

5- $\quad$ The normalized heat transfer coefficient at zero direction is greatest while for a direction of 90 o is lowest.

\section{REFERENCES}

BRE, "Ventilation requirements", Building Research Establishement Digest No. 206, Watford, 1997.

CIBSE A; Building Serv. Res. Technol. 20, "Assessing thermal comfort in ghadames”, Libya: Application of the Adaptive Model, 1999.
BS 5925,"code of practice for ventilation principles and designing for natural ventilation”, 1991.

Vicent M., Buhagair, and Phillip J. Jones, “An evaluation of natural ventilation regimes in refurbished historic buildings using wind tunnel modeling and CFD”, World Renewable Energy Congress VII, 2004.

Potangaroa R. T., "The natural ventilation potential of office buildings in the United States", World Renewable Energy Congress VII, 2004.

Hassan M.A. "Experimental and numerical study of the combined effects of outside environmantal conditions and openings on thermal comfort in buildings" Ph. D. Thesis, Faculty of Engineering, Shoubra, Zagazig university, Cairo, 2003.

Tine S.L., Per H. and Tako S., “ Analysis and design of single-sided natural ventilation”, The 4th International Symposium on HVAC Bejin, China, October 9-11,2003.

Axley J., Emmerich S. and Walton G., “ An Approach to the design of natural and hybride ventilation systems for cooling buildings", Indoor Air Procceding, USA, pp. 836-841, 2002.

Fernando M.. and Jorge G., “A Simplified Model to Estimate Natural Ventilation Flows for Simple Dwelling Layouts" , Journal of Ventilation, Paper 7, Volume 3 No.4, March 2005.

ANSYS, "FLOTRAN Analysis Guide", ANSYS, Inc. (2001).

Guirguis N. M., Hassan M. A., Shaalan M. R., and Hanna G. B., "Construction and testing of wind tunnel for in-door investigation of environmental effects on buildings", World Renewable Energy Congress IV, Denever, Colorado, USA, June 15-23, (1996).

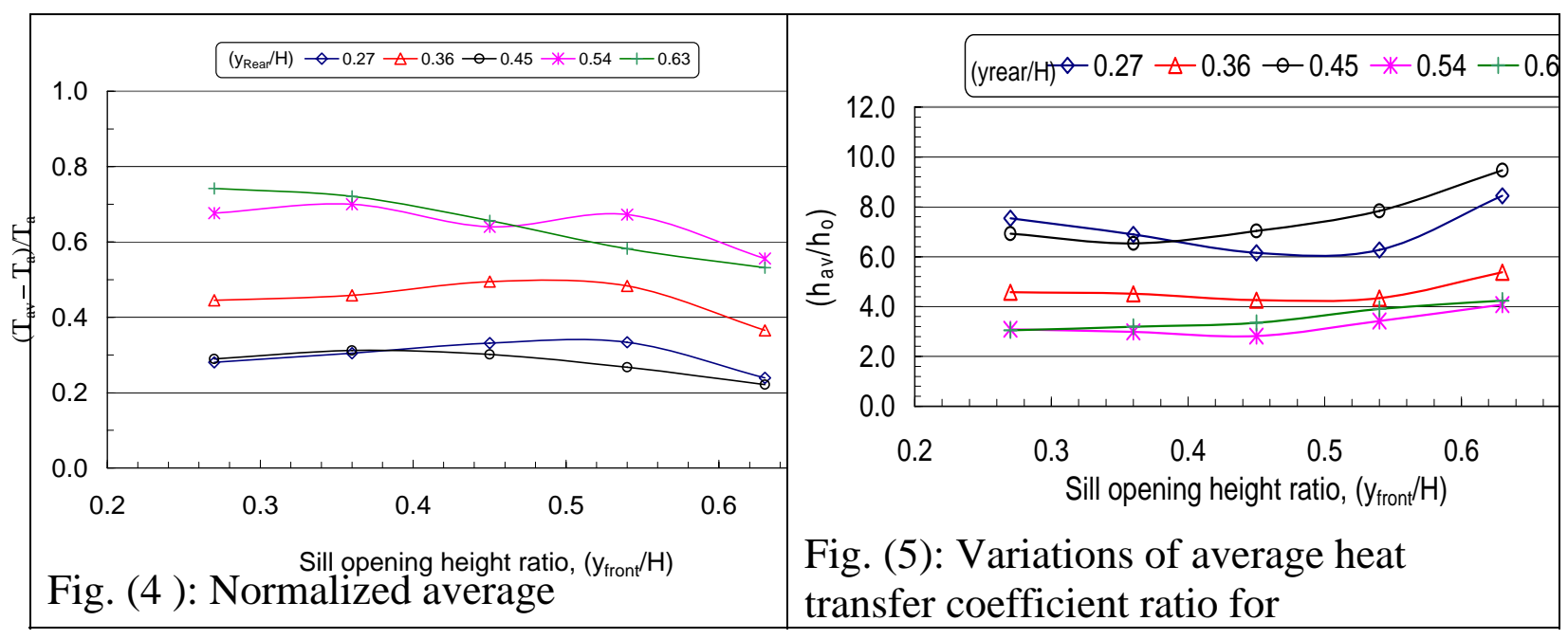



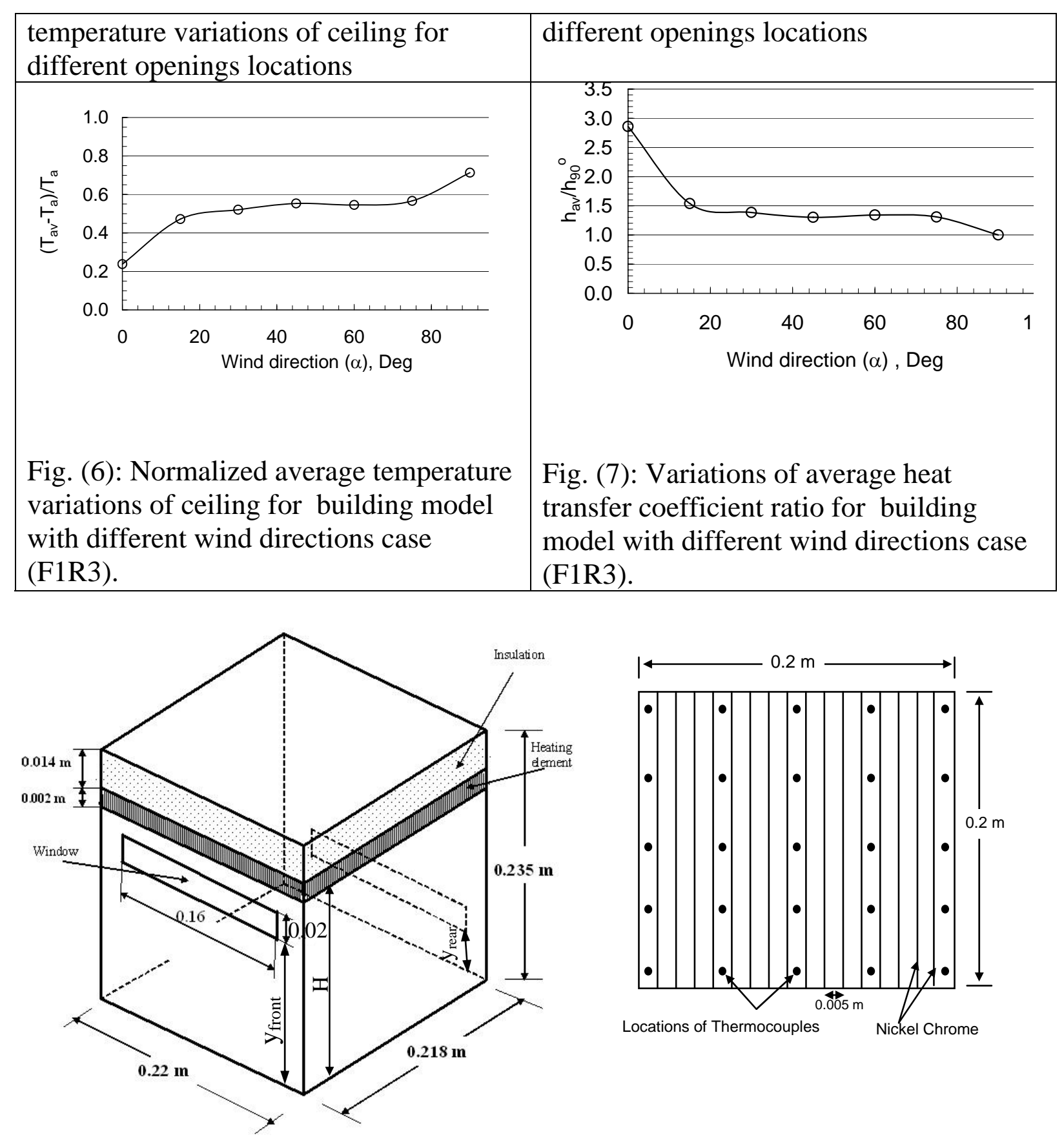


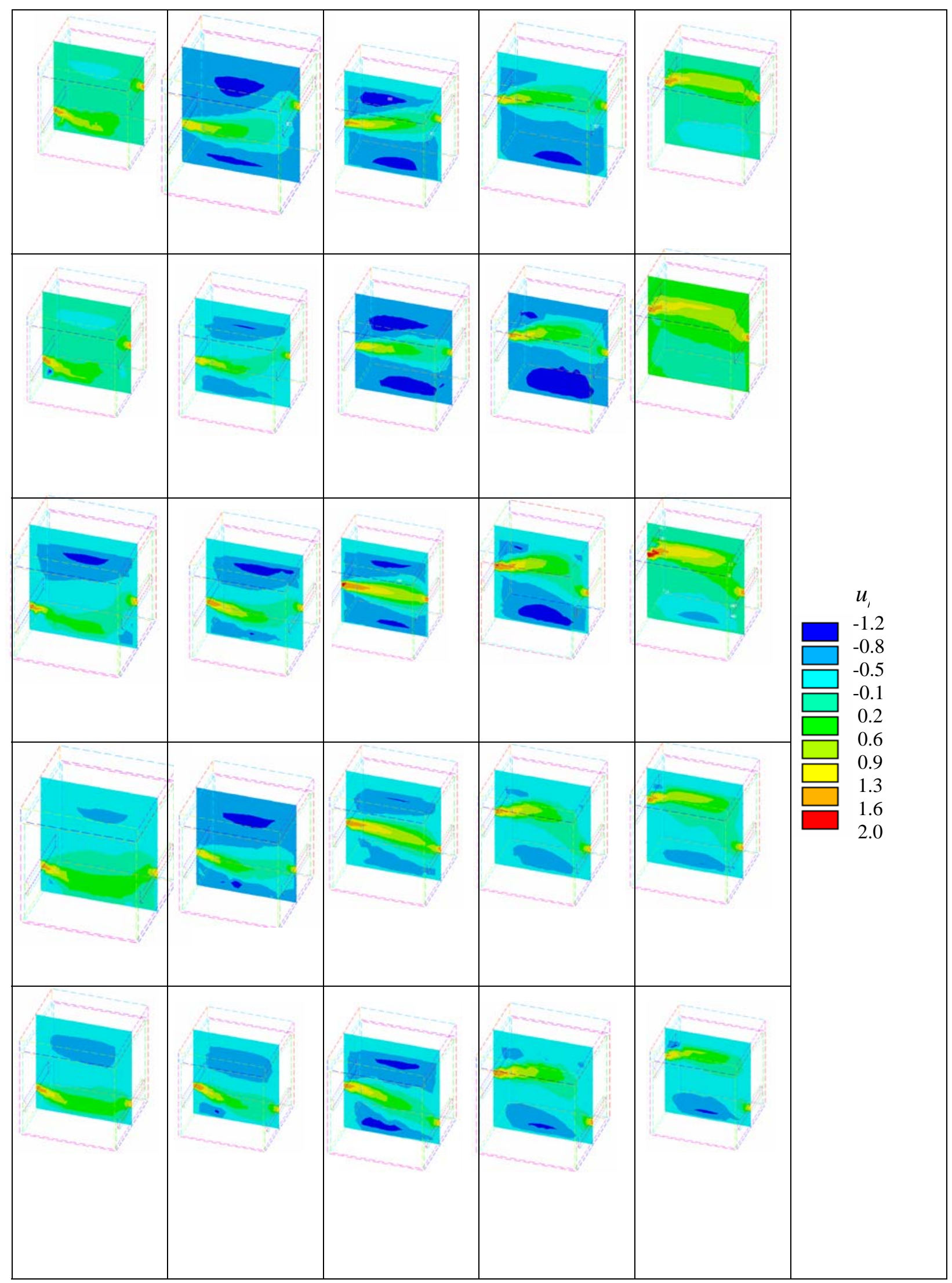

Fig (3): Velocity contours and vectors for 3-D geometrically similar rooms with different openings locations. 